\title{
Alterações fonético-fonológicas no latim do século I d.C: descrição do sistema vocálico latino a partir do Satyricon, de Petrônio
}

\author{
SANDRA MARIA GUALBERTO BRAGA BIANCHET \\ Departamento de Letras Clássicas \\ Faculdade de Letras \\ Universidade Federal de Minas Gerais
}

RESUMO: O estudo de transformações fonético-fonológicas de línguas que possuem apenas o registro escrito apresenta maiores dificuldades, uma vez que os manuscritos não são contemporâneos de seus autores. Apesar dessa limitação, procura-se demonstrar que é possível descrever o sistema vigente em determinado periodo da língua em estudo a partir da análise de textos como o Satyricon, em que o autor expressa diferentes registros de fala.

PALAVRAS-CHAVE: Petrônio; Satyricon; latim vulgar; fonética; fonologia; sistema vocálico.

\section{Introdução}

Os sons da fala podem ser abordados sob a perspectiva de duas ciências, em princípio, diferentes: a fonética e a fonologia. A distinção entre elas se baseia na diferenciação entre som, definido como unidade fônica em geral, e fonema, definido como unidade fônica funcional mínima, ou seja, uma imagem fônica capaz de distinguir um elemento lingüístico de outro (ex.: os sons representados pelas letras $b$ e $p$ em latim, que distinguem o vocábulo bello do vocábulo pello) (Maniet, 1975, p. 18). No entanto, identifica-se na lingúística moderna uma tendência a se unir estreitamente ambas as ciências, acrescentando aos estudos sobre fonética questões relativas à fonologia (Herrero, 1981, p. 327). A tendência a obliterar esta distinção se evidencia já nas definições de fonética apresentadas nos tratados sobre o assunto, como por exemplo em Niedermann (Niedermann, 1931, p. 3): "La phonétique est la science des phònemes qui constituent le langage" (grifo meu), ou em Maniet (Maniet, 1975, p. 17): "La phonétique est la science qui a pour objet les sons du langage articulé ou phonèmes" (grifo meu).

Uma das questões essenciais envolvendo os estudos sobre fonética/fonologia é o cuidado de não se confundirem os sons com as letras do alfabeto, signos convencionais que os representam na escrita, mas de maneira imperfeita (Maniet, 1975, p. 18; Herrero, 1981, 
190 Sandra Maria Gualberto Braga Bianchet: Alterações fonético-fonológicas no latim do século I d.C: descrição do sistema vocálico latino a partir do Satyricon, de Petrônio.

p. 337), já que podem existir, em uma mesma língua, várias grafias para um mesmo som e, pelo contrário, vários sons podem ser representados por uma única grafia.

A inexistência de um sistema fônico em que se pode identificar para cada som uma grafia leva a que se considerem os sons como autônomos em relação à grafia que os representa, ${ }^{1}$ gerando dificuldade principalmente nos estudos de fonética descritiva de línguas que possuem apenas o registro escrito (ex.: latim, grego antigo, português arcaico), que pressupõem a identificação da equivalência entre som/sons e grafia/grafias única e exclusivamente através de textos (Maniet, 1975, p. 18; Herrero, 1981, p. 338). Essa identificação se torna bastante complexa diante de dois fatores: em primeiro lugar, as línguas antigas não apresentam uma uniformidade ortográfica, ${ }^{2}$ a partir da qual se possam estabelecer tais correspondências; em segundo lugar, os manuscritos, que serviriam de base para descrever 0 sistema fônico em uso em determinado texto, não oferecem informações seguras, já que não são contemporâneos dos autores das obras e, por isso, podem ter sido alterados, apresentando o padrão ortográfico vigente em época bem posterior. ${ }^{3}$

Especificamente em relação ao latim, Desbordes (Desbordes, 1995, p. 143) afirma: "os fatores que determinam as grafias latinas são tão numerosos e tão dificilmente discerníveis que parecem efeito do acaso. Os modernos que tiveram algum interesse pela questão puderam apenas constatar uma incoerência desconcertante".

A falta de um padrão ortográfico a ser seguido em latim ${ }^{4}$ deixava aos escritores a liberdade de escolherem entre adotar o critério etimológico, pelo qual se procurava grafar 0 vocábulo atendendo à sua origem, ou o critério fonético, em que se tentava reproduzir a pronúncia (Faria, 1995, p. 41). Desbordes (Desbordes, op. cit., p. 152) generaliza a adoção desses critérios de acordo com o período da língua latina correspondente ao texto. Assim, na República coexistiriam as duas tendências, no início do Império teria havido a procura sistemática por uma ortografia legitimamente baseada na oralidade e, mais tarde, a opção pela ortografia baseada na autoridade dos antigos.

Em função desses dois critérios, os manuscritos não são tidos como fontes confiáveis para a reconstrução do sistema fônico do latim; o conhecimento deste apenas seria possível se se considerar: ${ }^{5}$

- o testemunho dos antigos gramáticos latinos (Varrão, Vélio Longo, Terenciano Mauro, dentre outros);

1 O princípio da autonomia entre som e grafia se baseia no principal axioma da lingŭística, qual seja, o princípio de que a relação entre som e significado é arbitrária (Palmer, 1954, p. 209).

2 Segundo Desbordes (Desbordes, 1995, p. 145), a preocupação com a uniformidade ortográfica é uma característica do homem moderno que se manifesta a partir do séc XIX.

3 Herrero (Herrero, 1981, p. 30) afirma que nenhum dos manuscritos clássicos conservados até 0 presente é autógrafo ou copiado durante a vida de seu autor.

4 Faria (Faria, 1957, p. 118) afirma: "não havia sistema uniforme de escrita seguido por todos os escritores (nunca houve em latim). Havet (Havet, apud Desbordes, 1995, p. 146) declara: "não existe ortografia latina. A própria palavra ortografia é um contra-senso quando se trata do latim".

5 Obras utilizadas para a enumeração das fontes consideradas confiáveis para a reconstrução do sistema fônico do latim: Maniet, 1975, p. 19; Herrero, 1981, p. 338; Faria, 1995, p. 42. 
- as observações ocasionais de outros autores latinos, tais como Cícero e Quintiliano, sobre questões de fonética;

- a escrita fonética de muitas inscrições latinas;

- as grafias gregas de palavras ou de nomes latinos, e vice-versa;

- a comparação do latim com as línguas românicas.

Apesar das restrições em relação ao estudo de questões fonéticas com base em textos tais como o Satyricon, cujos manuscritos podem ter sido alterados no decurso da transmissão, parte-se, no presente estudo, do princípio de que esses textos podem efetivamente fornecer dados acerca do padrão fonético vigente à época, uma vez que podem apresentar interferência do registro oral na modalidade escrita da língua latina. Dessa maneira, utilizase a obra Satyricon como fonte confiável para identificação e estudo de alterações fonéticofonológicas características do século I d.C., ocorridas no sistema vocálico latino.

\section{O sistema vocálico latino}

O sistema vocálico do latim clássico, em que predominam as qualidades físicas de quantidade e altura, é composto por duas séries de cinco vogais cada uma, diferentes entre si apenas pela duração da pronúncia em um tempo (vogais breves $\breve{a}, \breve{e}, \grave{i}, \breve{o}, \breve{u}$ ), ou em dois (vogais longas $\bar{a}, \bar{e}, \bar{i}, \bar{o}, \bar{u}$ ) (Palmer, 1954, p. 156; Rohlfs, 1963, p. 42; Maniet, 1975, p. 22). Combinadas entre si, duas vogais de timbre diferente, mas com uma única tensão, formam ditongos, que em latim clássico são três: ae, oe, au (Maniet, 1975, p. 25; Machado, 1940, p. 84; Niedermann, 1931, p. 82). Na transliteração de palavras tomadas de empréstimo ao grego contendo a vogal -u-, havia ainda o emprego da letra - $y-$-, estranha ao alfabeto latino, no lugar da correspondente latino -u- (Väänänen, 1985, p. 81). ${ }^{6}$

A quantidade longa ou breve das vogais representava uma distinção fonêmica em latim clássico, isto é, se constituía em única marca de diferenciação entre duas formas de um mesmo vocábulo (Palmer, 1954, p. 155; Maniet, 1975, p. 22), como, por exemplo, nos pares abaixo:

a) rosă-nominativo singular de tema em -a e rosā - ablativo singular de tema em $-a$;

b) lĕgit - presente do indicativo e lēgit - pretérito perfeito do indicativo. ${ }^{7}$

Através do confronto com as línguas românicas e de descrições de gramáticos antigos, pode-se dizer que, na pronúncia, a diferença entre vogais longas e breves se mani-

6 Segundo Faria (Faria, 1995, p. 30), a letra grega -y- era pronunciada em latim com o mesmo valor que tinha na língua original, que equivaleria ao som do -u- no francês atual.

7 É importante ressaltar que, em ambos os pares, a distinção fonêmica baseada na quantidade resulta em uma diferenciação morfológica de um mesmo vocábulo. Para Palmer (Palmer, 1954, p. 155), a eliminação da distinção fonêmica com base na quantidade é a mais importante modificação ocorrida no sistema vocálico do latim vulgar. 
festava pelo timbre mais fechado com que se produziam as vogais longas (Maniet, 1975, p. 22). ${ }^{8}$

As mudanças no sistema vocálico do latim, descrito de maneira sucinta acima, que se processaram no latim vulgar, envolvem duas grandes transformações: a eliminação da noção de quantidade e a generalização do processo de monotongação.

O novo sistema vocálico passou a compreender uma série de vogais, diferenciadas entre si pelo grau de abertura ( $a$, e aberto, e fechado, i, o aberto, o fechado, $u$ ) (Palmer, 1954, p. 156; Rohlfs, 1963, p. 42). Essas alterações se refletem nos textos através da instabilidade na grafia, principalmente de vogais átonas, pré e pós-tônicas, em sílaba intermediária, que podem desaparecer completamente (processo fonético denominado de síncope); ou ter seu timbre modificado (processo que recebe a denominação de apofonia).

A ocorrência de síncope é, em geral, associada à rapidez com que se pronunciavam as sílabas breves átonas, na linguagem familiar em latim (Niedermann, 1931, p. 47; Väänänen, 1985, p. 89). ${ }^{9}$ No entanto, a síncope, comum principalmente em sílabas posteriores à sílaba tônica (como por exemplo em calídus/caldus), ${ }^{10}$ não é um processo que possa ser considerado como "mudança lingüística", ou "lei fonética", uma vez que atinge de maneira irregular os diversos vocábulos que apresentam o mesmo ambiente fonético, favorável a sua ocorrência, o que não permite que se estabeleça com precisão quando o fenổmeno deve ou não ocorrer (Maniet, 1975, p. 132; Väänänen, 1985, p. 87).

A apofonia, modificação do timbre das vogais breves em sílaba medial, é um fenômeno típico da língua clássica, que passa a ocorrer de maneira mais geral e assistemática no latim vulgar, condicionado pelo lugar que a vogal ocupa na palavra e por efeito da intensidade inicial das palavras (Juret, 1913, p. 256; Niedermann, 1931, p. 27; Herrero, 1981, p. 343). O timbre mais ou menos fechado ( $u$ ou $i$, respectivamente) que a vogal passa a assumir varia conforme a consoante seguinte (Machado, 1940, p. 76). ${ }^{11}$

Também o processo de monotongação se tornou geral em latim a partir de contextos em que o ditongo se encontrava em sílabas átonas, já no período republicano, tendo-se estendido para as sílabas tônicas no séc. I d.C. (Palmer, 1954, p. 156). Este processo representa a manutenção de uma tendência evidente em latim desde o começo da tradição escrita, quando o grupo de cinco ditongos (ou, oi, ei, $a i, a u$ ) se reduziu a três no latim clássico (Väänänen, 1985, p. 83). Apenas um dos três ditongos do latim clássico (o diton-

8 Maurer Jr (Maurer Jr, 1959, p. 10-1) apresenta discussão sobre o timbre das vogais longas e breves, a partir de autores que questionam a associação entre vogal longa/timbre fechado e vogal breve/timbre aberto.

9 Para Jespersen (Jespersen, 1949, p. 328), a síncope é um processo, presente em todas as línguas, que reflete a tendência fonética universal de encurtar as palavras.

10 A forma plena calídum é qualificada de pedante (otiosum) por Quintiliano (Quintiliano, Inst. Orat. I, 6, 19).

"Williams (Williams, 1961, p. 17) descreve um processo puramente ortográfico de modificação de $e$ em $i$ e de $o$ em $u$, freqüente em documentos do latim medieval, que decorre de confusão entre essas duplas de letras, e que não deve ser confundido com casos de apofonia. 
go $a u$ ) permaneceu como ditongo até nas línguas românicas; os demais ditongos - ae e oe - se tornaram $e$ aberto e $e$ fechado, respectivamente (Climent, 1962, p. 74-6). ${ }^{12}$

\section{O sistema vocálico latino descrito a partir do Satyricon}

A partir da discussão apresentada acima acerca das principais alterações fonéticas ocorridas no sistema vocálico do latim vulgar, os pontos de divergência identificados ao longo do Satyricon em relação ao padrão clássico serão listados para análise em três tabelas, que expressam o processo fonético envolvido:
a) tabela $\mathrm{A}$ - síncope; ${ }^{13}$
b) tabela $\mathrm{B}$ - apofonia; ${ }^{14}$
c) tabela $\mathrm{C}$ - monotongação.

Cada uma das tabelas está organizada em três colunas, em ordem alfabética. A primeira coluna contém as formas padrão e/ou alteradas, estas últimas apenas nos casos em que se encontrem indicadas em verbete separado nos dicionários consultados (basicamente Lewis \& Short, 1987; Gaffiot, 1934), seguidas de sua tradução na(s) acepção(ções) utilizada(s) por Petrônio. A segunda coluna traz as formas alteradas identificadas no texto do Satyricon e a terceira lista as formas padrão presentes na obra, cada uma das ocorrências acompanhada da indicação de sua localização no texto (capítulo e subdivisão de capítulo).

12 Apesar das evidências contrárias apresentadas pela evolução do ditongo au nas línguas românicas (ex. a forma latina aurum, que evoluiu para ouro - pronunciado oro - em português, para oro em espanhol e para or em francês) os estudiosos são unânimes em afirmar que o processo de monotongação do ditongo $a u$ em o, que ocorre em textos latinos, é a expressão de uma pronúncia considerada rústica, que teria penetrado em Roma nos séc. II e I d. C., principalmente nas camadas mais baixas (Climent, 1962, p. 74) e seria um processo diferente da posterior monotongação de au nas diferentes línguas românicas (Palmer, 1954, p. 156; Väänänen, 1985, p. 85). O único caso de monotongação de au reconhecido por esses estudiosos como próprio do latim vulgar e que teria chegado às línguas românicas é o que ocorre, por exemplo, na passagem de Augustus para Agustus.

13 Diferentemente de Niedermann (Niedermann, 1931, p. 49), não foram listados como casos de síncope os compostos de iacere grafados com apenas um $i$ (ex.: proicere, coniciet, conicias, deiciebat, coniciamus), uma vez que estes foram considerados como contração de vogais (crase), após a apofonia de $a$ para $i$.

${ }^{14}$ Foram selecionados para composição das tabelas apenas os vocábulos em que a apofonia não está prevista como fenômeno da língua clássica. 
Sandra Maria Guaiberto Braga Bianchet: Alterações fonético-fonológicas no latim do século I d.C: descrição do sistema vocálico latino a partir do Satyricon, de Petrônio.

A) Síncope

\begin{tabular}{|c|c|c|}
\hline Verbete & Forma sincopada & Forma plena \\
\hline $\begin{array}{l}\text { 1. } \begin{array}{l}\text { bŭbulus, }-\mathrm{a},- \text {-um: } \\
\text { relativo ao boi }\end{array}\end{array}$ & bublum $(44,12$ & bubulae $(35,3)$ \\
\hline $\begin{array}{l}\text { 2. calefăcio, -feci, - } \\
\text { factum: aquece }\end{array}$ & $\begin{array}{l}\text { calfacti }(28,1) \\
\text { calfeci }(41,11\end{array}$ & - \\
\hline $\begin{array}{l}\text { 3. calídus } \text { - -a, um: } \\
\text { quente }^{i 5}\end{array}$ & $\begin{array}{l}\text { caldum }(66,3)(67,10) \\
\text { caldam }(65,7)(68,3) \\
\text { calda }(41,11\end{array}$ & \\
\hline $\begin{array}{l}\text { 4. dexter, -ĕra, -ĕrum } \\
\text { direito }\end{array}$ & $\begin{array}{l}\text { dextrum }(32,4) \\
\text { dextro }(30,5) \\
\text { dextros }(30,7)(30,9) \\
\text { dextram }(121,1,100)(122 \\
1,167)(133,2,8) \\
\text { dextrae }(121,1,100) \\
\text { dextra }(124,1,263)(124,1 \\
277)(134,5)\end{array}$ & $\begin{array}{l}\text { dexteram }(71,11)(74 \\
\text { 2) }\end{array}$ \\
\hline $\begin{array}{l}\text { 5. fericŭlum/fercūlum, - } \\
\text { i }(n) \text { : bandeja }\end{array}$ & $\begin{array}{l}\text { ferculis }(21,7) \\
\text { ferculo }(41,9) \\
\text { ferculum }(35,1)(39,1)(66, \\
3 \text { ) }\end{array}$ & $\begin{array}{l}\text { fericulo }(68,2) \\
\text { fericulum }(60,7)(69, \\
7) \\
\text { fericulus }(39,4)\end{array}$ \\
\hline $\begin{array}{l}\text { 6. lămina, -ae (f): } \\
\text { lâmina }\end{array}$ & \begin{tabular}{|l|} 
lamna $(57,4)$ \\
lamnam $(58,8)$
\end{tabular} & lamina $(32,4)$ \\
\hline $\begin{array}{l}\text { 7. offüla, -ae }(\mathfrak{f}): \\
\text { pequeno pedaço }\end{array}$ & $\begin{array}{l}\text { offla }(56,8)(58,2) \\
\text { offlam }(56,9)\end{array}$ & - \\
\hline $\begin{array}{l}\text { 8. } \begin{array}{l}\text { pedicŭlus, }-\mathrm{i}(\mathrm{m}) \\
\text { piolho }\end{array}\end{array}$ & peduclum $(57,7)$ & - \\
\hline $\begin{array}{l}\text { 9. ridicülus, -a, -um: } \\
\text { ridículo }\end{array}$ & ridiclei $(57,8)$ & ridiculum $(54,3)$ \\
\hline $\begin{array}{l}\text { 10. scribilita/scriblitta, - } \\
\text { ae (f): pastel de } \\
\text { queijo }\end{array}$ & scriblita $(35,4)$ & sciribilita (66, 3 - bis) \\
\hline $\begin{array}{l}\text { 11. stipěs, -itis (m): } \\
\text { idiota }\end{array}$ & stips $(43,5)$ & $\begin{array}{l}\text { stipite }(124,1,263) \\
(136,2\end{array}$ \\
\hline $\begin{array}{l}\text { 12. struthiocamelus, i } \\
(\mathrm{m}) \text { avestruz }\end{array}$ & struthocamelus $(137,4)$ & - \\
\hline $\begin{array}{l}\text { 13. uincŭlum, -i (n): } \\
\text { corda }\end{array}$ & uincla $(102,12)$ & $\begin{array}{l}\text { uinculo }(97,5)(102,1) \\
\text { uinculum }(114,12) \\
(126,17) \\
\text { uincula }(123,1,188) \\
(136,4)\end{array}$ \\
\hline
\end{tabular}

15 Como o adjetivo caldicerebrius $(45,5$ e 58,4$)$ ocorre apenas sob a forma sincopada, considerou-se que este neologismo de Petrônio tenha sido formado a partir de caldus e não de calidus, motivo pelo qual foi excluído da listagem. 
B) Apofonia

\begin{tabular}{|c|c|c|}
\hline Verbete & Forma alterada & Forma padrão \\
\hline $\begin{array}{l}\text { 1. } \begin{array}{l}\text { apoculo, -aui, -atum } \\
\text { desaparecer }\end{array} \\
\text { a }\end{array}$ & apocalo $(67,3)$ & apoculamus $(62,3)$ \\
\hline $\begin{array}{l}\text { 2. camera, -ae (f) } \\
\text { arco }\end{array}$ & camaram $(40,1)$ & $\begin{array}{l}\text { camera }(30,3) \\
\text { cameram }(73,3)\end{array}$ \\
\hline $\begin{array}{l}\text { 3. cauněae, -arum (f): } \\
\text { figos secos (d } \\
\text { cidade de Caunus) }\end{array}$ & cauniaru $\quad(44,13$ & - \\
\hline $\begin{array}{l}\text { 4. Corinthĭus, -a, -um: } \\
\text { de Corinto }\end{array}$ & $\begin{array}{l}\text { Corinthea }(50,2)(50,4)(50 \\
5)(50,6) \\
\text { Corintheu }(50,4)\end{array}$ & $\begin{array}{l}\text { Corinthius }(31,9) \\
\text { Corinthia }(50,1)\end{array}$ \\
\hline $\begin{array}{l}\text { 5. cymba, -ae (f): } \\
\text { barca }\end{array}$ & cumba $(121,1,118$ & - \\
\hline $\begin{array}{l}\text { 6. decímus, -a, -um: } \\
\text { décimo }\end{array}$ & $\begin{array}{l}\text { decuma }(37,9) \\
\text { decuma }(89,1,1)\end{array}$ & - \\
\hline $\begin{array}{l}\text { 7. diuerbǐum, -ii (n): } \\
\text { diálogo }\end{array}$ & deuerbia $(64,2)(64,4)$ & - \\
\hline $\begin{array}{l}\text { 8. dupondiarius, }-\mathrm{a},- \\
\text { um: sem valor }\end{array}$ & $\begin{array}{l}\text { dupunduarius }(58,4) \\
\text { dipundiarius }(74,15\end{array}$ & \\
\hline $\begin{array}{l}\text { 9. dupondius, }-\mathrm{ii}(\mathrm{m}) \text { : } \\
\text { dois asses }\end{array}$ & $\begin{array}{l}\text { dipondium }(14,3) \\
\text { dupundii }(58,4)\end{array}$ & dupondii $(58,14$ \\
\hline 10. huc para aqui & $\operatorname{hoc}(39,8)$ & $\begin{array}{l}\text { huc }(17,9)(23,3,1-\text { bis } \\
(37,1)(77,5)(79,2)(80, \\
2)(89,1,8)(101,5)(113, \\
8)(114,3)(133,2,5 \\
(141,8\end{array}$ \\
\hline 11. illuc: ali & illoc $(39,8)$ & $\begin{array}{l}\text { illuc }(37,1)(101,5)(114, \\
3)\end{array}$ \\
\hline $\begin{array}{l}\text { 12. inclūtus, -a, -um: } \\
\text { ilustre }\end{array}$ & inclita $(133,2,2)$ & - \\
\hline $\begin{array}{l}\text { 13. ipsimus, -a, um: } \\
\text { o(a) dono(a) da } \\
\text { casa }\end{array}$ & ipsumam $(69,3)$ & $\begin{array}{l}\text { ipsimi }(63,3)^{*},(75,11 \\
(76,1) ; \text { ipsimae }(75,11\end{array}$ \\
\hline 14. istuc: para aí & istoc $(57,10$ & - \\
\hline $\begin{array}{l}\text { 15. lacrima, -ae (f) } \\
\text { lágrima }\end{array}$ & $\begin{array}{l}\text { lacrumas }(9,2) \\
\text { lacrumis }(91,4)\end{array}$ & $\begin{array}{l}\text { lacrimas }(17,2)(18,1 \\
(24,1)(57,1)(75,3)(89, \\
1,17)(91,8)(105,11 \\
(110,3)(111,4)(111,8) \\
(115,12) \\
\text { lacrimis }(18,4)(81,1)(99, \\
\text { 2) }(101,8)(134,5) \\
\text { lacrimae }(113,9 \\
\text { lacrimarum }(117,6\end{array}$ \\
\hline $\begin{array}{l}\text { 16. lineamentum, }-i(n) \\
\text { traç }\end{array}$ & liniamenta $(110,2$ & - \\
\hline
\end{tabular}


196 Sandra Maria Guaiberto Braga Bianchet: Alteraçōes fonético-fonológicas no latim do século I d.C: descrição do sistema vocálico latino a partir do Satyricon, de Petrônio.

\begin{tabular}{|c|c|c|}
\hline $\begin{array}{l}\text { 17. monumentum, }-i(n) \text { : } \\
\text { monumento }\end{array}$ & monimenta $(62,4)$ & $\begin{array}{l}\text { monumenta }(65,5)(111, \\
6) \\
\text { monumentu }(71,5)(71, \\
7)(71,8)(111,8)(112,3 \\
(112, \quad 4) \quad(113, \quad 2) \\
\text { monumenti }(71,9)(74,17 \\
(111,4\end{array}$ \\
\hline $\begin{array}{l}\text { 18. nausēa, -ae (f): } \\
\text { enjôo }\end{array}$ & nausia $(74,6)$ & $\begin{array}{l}\text { nausea }(78,5) \\
\text { nausea }(103,5\end{array}$ \\
\hline $\begin{array}{l}\text { 19. neglëgens, entis } \\
\text { indiferente }\end{array}$ & negligens $(128,1)$ & - \\
\hline $\begin{array}{l}\text { 20. ossiculüm, - } i(n) \text { : } \\
\text { ossinho }\end{array}$ & ossucula $(65,11)$ & - \\
\hline $\begin{array}{l}\text { 21. paratissimus, -a, - } \\
\text { um: muito be } \\
\text { preparado }\end{array}$ & paratissumus $(31,6)$ & $\cdot$ \\
\hline $\begin{array}{l}\text { 22. pedicülus, }-i(m) \\
\text { piolho }\end{array}$ & peduclu $(57,7)$ & - \\
\hline $\begin{array}{l}\text { 23. pertracto, -aui, - } \\
\text { atum: toca }\end{array}$ & pertrectau $(79,10)$ & pertractato $(24,7)$ \\
\hline $\begin{array}{l}\text { 24. praefiscine } \\
\text { inofensivo }\end{array}$ & praefiscini $(73,6)$ & - \\
\hline $\begin{array}{l}\text { 25. regimen, -inis }(n) \\
\text { direção }\end{array}$ & regumen $(123,1,235$ & - \\
\hline $\begin{array}{l}\text { 26. robigo, -inis }(f) \\
\text { ferrugem }\end{array}$ & rubigine $(124,1,274$ & - \\
\hline $\begin{array}{l}\text { 27. tricenties: trezenta } \\
\text { vezes }\end{array}$ & $\begin{array}{l}\text { trecenties }(71,12)(76,4) \\
(88,8)(117,8)\end{array}$ & tricenties $(45,6)$ \\
\hline $\begin{array}{l}\text { 28. ualetudo, -inis ( } f \text { ) } \\
\text { saúde }\end{array}$ & ualitudine $(61,1)(88,8)$ & - \\
\hline $\begin{array}{l}\text { 29. uulpes, -is ( } f) \\
\text { raposa }\end{array}$ & uolpis $(58,12)$ & uulpes $(44,14)$ \\
\hline
\end{tabular}


C) Monotongação

\begin{tabular}{|c|c|c|}
\hline Verbete & Forma monotongada & Forma ditongada \\
\hline $\begin{array}{l}\text { 1. auricularius, -a, um: } \\
\text { profético }\end{array}$ & oricularios $(43,6)$ & - \\
\hline $\begin{array}{l}\text { 2. cauda, -ae (f): } \\
\text { cauda }\end{array}$ & $\operatorname{coda}(44,12)$ & cauda $(89,1,38)$ \\
\hline $\begin{array}{l}\text { 3. caudex, ícis }(m) \text { : } \\
\text { tronco de árvore }\end{array}$ & $\operatorname{codex}(74,13)$ & caudice $(135,8,6)$ \\
\hline $\begin{array}{l}\text { 4. cauliculús/colicŭlus } \\
\text { (m): caule }\end{array}$ & coliculi $(132,8,2)$ & - \\
\hline $\begin{array}{l}\text { 5. caupo, -onis }(\mathrm{m}) \text { : } \\
\text { taberneiro }\end{array}$ & $\begin{array}{l}\text { copones }(39,12)(61,6) \\
\text { copo }(62,12)\end{array}$ & cauponi $(98,1)$ \\
\hline $\begin{array}{l}\text { 6. claudo, clausi, } \\
\text { clausum: fechar }\end{array}$ & $\begin{array}{l}\text { clusissem }(57,2) \\
\text { cluso }(63,8)\end{array}$ & $\begin{array}{l}\text { clausus }(55,6,2) \\
\text { claudit }(122,1,147) \\
\text { clausum }(137,9,10)\end{array}$ \\
\hline $\begin{array}{l}\text { 7. lautus, -a, -um: } \\
\text { lavado, louvável }\end{array}$ & $\begin{array}{l}\text { Iota }(30,11) \\
\operatorname{lotam}(40,7)\end{array}$ & $\begin{array}{l}\text { lauta }(31,8) \\
\text { lautum }(65,10) \\
\text { lautas }(137,12)\end{array}$ \\
\hline $\begin{array}{l}\text { 8. nenĭa/naeňa, -ae } \\
\text { (f): canto fúnebre }\end{array}$ & nenias $(46,4)(47,10)$ & naenias $(58,7)$ \\
\hline 9. paene: quase & pene $(136,6)$ & $\begin{array}{l}\text { paene }(15,2)(29,1)(33, \\
7)(62,10)(64,3)(64,9) \\
(66,5)(70,11)(79,3)(88, \\
5)(92,6)(100,4)(113,9) \\
(115,11)(126,15)(140, \\
6)\end{array}$ \\
\hline $\begin{array}{l}\text { 10. plaudo, plausi, } \\
\text { pausum: aplaudir }\end{array}$ & plodo $(45,13)$ & $\begin{array}{l}\text { plaudentibus }(25,3) \\
\text { plaudentes }(26,1) \\
\text { plaudentem }(67,5) \\
\text { plaudebat }(70,10) \\
\text { plaudente }(119,1,18)\end{array}$ \\
\hline $\begin{array}{l}\text { 11. scaena, -ae (f): } \\
\text { cena }\end{array}$ & $\begin{array}{l}\text { scenam }(5,1,7)(33,5) \\
\text { scena }(117,2)\end{array}$ & $\begin{array}{l}\text { scaena }(80,9,5) \\
\text { scaenae }(117,10)(126,6)\end{array}$ \\
\hline
\end{tabular}




\section{Análise dos dados}

As alterações no sistema vocálico do Satyricon, identificadas a partir de divergências entre a forma grafada no texto e a forma indicada como padrão nos dicionários consultados, refletem, por um lado, as tendências gerais apresentadas na discussão que antecede a listagem, mas, por outro lado, apresentam alguns dados ainda não levados em consideração.

Em relação ao processo de síncope, observa-se que as ocorrências das formas sincopadas se concentram nos capítulos relativos ao grupo de episódios em que se narra a Cena Trimalchionis e no poema sobre a guerra civil (capítulos 119 a 124) e reafirmam a tendência de se realizar a síncope nas vogais e, i, u pós-tônicas em sílaba medial (vocábulos 1 bublum, 3 - caldum, 4 - dextrum, 6 - lamna, 7 - offla, 8 - peduclum, 9 - ridicleie 13 - uincla). O vocábulo 9 traz ainda uma outra alteração da forma clássica, a saber, a inclusão da vogal epentética - $e$ - na última sílaba, um fenômeno que pode ser identificado ao de "diferenciação", tal como definido em Maniet (Maniet, 1975, p. 79), semelhante ao de dissimilação. As razões que levam ao emprego das formas sincopadas nesses contextos são motivadas pela diminuição de uma sílaba que ocorre quando há a síncope e resultam em maior rapidez na pronúncia, no caso dos diálogos e narrações dos episódios da Cena, além de permitir moldar o vocábulo segundo a métrica, para os poemas. No entanto, as formas plenas são também freqüentes nos mesmos grupos de episódios, o que confirma que a síncope não se caracteriza como "lei fonética", mas como um recurso de que o falante/escritor lança mão de maneira assistemática. Os demais vocábulos apresentam síncope em vogais tőnicas (ocorrência 5-ferculis), pré-tônicas (ocorrências 2-calfacti, 10-scriblita e 12struthocamelus) e pós-tônicas (ocorrência 11-stips), aos quais se aplica a mesma motivação de diminuição de uma sílaba. ${ }^{16}$

Os casos de apofonia listados na tabela B envolvem, em sua maioria, a alteração de timbre em três pares de vogais:

a) -e-/-i- (vocábulos 3 - cauniarum, 4 - Corinthea, 7 - deuerbia, 16 - liniamenta, 18 - nausia, 19 - negligens, 24 - praefiscini, 27 - trecenties e 28 - ualitudinem);

b) -i-/-u- (vocábulos 6 - decumam, 8 - dipundiarius, 9 - dipondium, 12 - inclita, 13 - ipsumam, 15 - lacrumas, 17 - monimenta, 20 - ossucula, 21 paratissumus, 22 - peduclum e 25 - regumen);

c) -o-/-u- (vocábulos 8 - dupundiarius, 9 - dupundii, 10 - hoc, 11 - illoc, 14 istoc, 26 - rubigine e 29 - uolpis).

As demais formas (vocábulos 1 - apocalo, 2 - camaram, 5 - cumba e 23 pertrectaui) apresentam, respectivamente, as seguintes alterações de timbre: -a-/-u-, -a-/-e-, $-\mathrm{u}-/-\mathrm{y}-\mathrm{e}$, novamente, $-\mathrm{a}-/-\mathrm{e}-$. Nos diversos pares em que ocorre a apofonia, não se pode

16 É interessante notar que a ocorrência 10 apresenta o movimento contrário ao de diminuição de sílaba, uma vez que a forma plena sciribilita, empregada duas vezes em sequiência na fala de Habinas, possui duas sílabas a mais, por causa da inserção de um - $i$ - entre as consoantes - $c$ - e $r$ - que não pode ser justificado, senão por hipercorreção. 
indicar uma direção única para a alteração do timbre das vogais (-o- muda para -u- e viceversa, por exemplo), nem identificar o contexto favorável a sua ocorrência. Esta falta de sistematicidade se deve à influência de fatores não fonéticos sobre a escolha da grafia que melhor representa os sons vocálicos que se deseja reproduzir em latim, modificando a tendência geral de que as vogais de timbre mais aberto tendem a se fechar, tomando um grau de abertura menor, numa escala que vai de -a- até -u-. São eles:

a) a força da grafia etimológica;

b) o emprego de grafias arcaicas;

c) a oscilação de emprego dos padrões ortográficos gregos, ou latinos na grafia de palavras tomadas de empréstimo ao grego.

A força da grafia etimológica se evidencia, por exemplo, nos vocábulos 7 e 27 (deuerbia por diuerbia, trecenties por tricenties), em que a forma clássica, com timbre mais fechado, é substituída por uma forma com timbre mais aberto, devido à suposição de que esses vocábulos teriam em sua formação o prefixo de- e o numeral tres, que são reproduzidos na escrita. Como exemplos de emprego de grafias arcaicas, podem-se citar os vocábulos 6 e 15 (decumam e ipsumam), empregados no texto sob a forma com o grau máximo de fechamento, apesar da forma clássica em -i-, um fenômeno recorrente no Satyricon em todos os grupos de episódios. A oscilação na grafia de palavras tomadas de empréstimo ao grego não reflete, propriamente, o fenômeno da apofonia, mas está relacionada a ele por envolver a alteração do timbre das vogais, como, por exemplo, no vocábulo 2 , que é utilizado no Satyricon sob as formas camera(m) e camara, esta última em função da forma grega $\kappa \alpha \mu \alpha ́ \alpha \alpha$.

O processo de monotongação, identificado no Satyricon, envolve apenas os ditongos -au- e -ae-, que passam, respectivamente, a -o-/-u- e -e-. Os vocábulos 1, 2, 3, 4, 5, 7 e 10 exemplificam a monotongação de -au- em -o-, considerada como uma marca de rusticidade (cf. discussão feita acima na seção "O Sistema Vocálico Latino"), o que é confirmado pelo fato de as formas monotongadas ocorrerem quase que exclusivamente nos episódios da Cena Trimalchionis (à exceção do vocábulo 4), em oposição ao emprego das formas ditongadas nos episódios finais (capítulos 79 a 141); essa diferenciação permite que a monotongação de -au- em -o- ao longo da obra seja analisada como um recurso estilístico utilizado por Petrônio, para caracterizar a fala dos personagens. ${ }^{17}$ Por outro lado, a frequência com que a monotongação de -au- em -o- ocorre em diferentes vocábulos e na fala de diferentes personagens demonstra que esse processo era comum na linguagem oral e leva a que seja considerado como característico do latim vulgar, o que contradiz a posição assumida na bibliografia consultada e apresentada anteriormente em relação ao processo de monotongação de -au- em latim e nas línguas românicas. A monotongação de -au- em -u-

${ }^{17}$ Os vocábulos 2,3 e 5 deixam bem marcada esta diferenciação, uma vez que as formas monotongadas (coda, codex, copo/copones) ocorrem nos episódios da Cena, ao passo que as formas com ditongo (cauda, caudice, cauponi) ocorrem nos episódios finais. 
ocorre apenas no vocábulo 6 e pode ser creditada à analogia com as formas compostas do verbo claudo (por exemplo, excludo). A análise dos vocábulos que apresentaram a alteração de -ae- para -e- (itens 8, 9 e 11) demonstra que, diferentemente do ditongo -au-, o processo de monotongação não pode ser caracterizado como um recurso estilístico, uma vez que as formas com e sem ditongo ocorrem indistintamente ao longo de todos os grupos de episódios.

\section{Conclusão}

Em linhas gerais, as alterações fonético-fonológicas listadas acima, reveladas pela ortografia, podem ser analisadas como reflexo de duas tendências: uma de caráter arcaizante, outra de caráter inovador. A primeira se mostra presente na utilização de formas e padrões dos séculos II e I a.C., revelando a primazia do critério ortográfico sobre o fonético; a segunda apresenta formas mais recentes, características do séc. I de nossa era, que podem ser vistas como a tentativa de se escrever como se fala, tornando a escrita um reflexo da língua falada (critério fonético).

A dificuldade de se afirmar que as grafias selecionadas para análise eram efetivamente as utilizadas pelos grupos sociais do século I d.C. retratados no Satyricon reside no fato de que os manuscritos, não sendo contemporâneos do autor, podem ter sido alterados (e provavelmente o foram) no decorrer de sua transmissão. Apesar dessa restrição, foi possível identificar algumas alterações no sistema vocálico como comprovadamente características da linguagem popular do século I d.C., uma vez que Petrônio as emprega de maneira seletiva e estratégica, no grupo de episódios em que narra a Cena Trimalchionis e, com isso, demonstrar a validade da utilização de textos literários tais como o Satyricon para estabelecimento do padrão fonético-fonológico em uso.

As ocorrências de síncope e algumas das ocorrências de monotongação demonstraram estar sendo utilizadas como recurso estilístico por Petrônio, o que dá mais garantia de que sejam realmente relativas ao padrão fonético vigente no séc. I d.C.; os dados permitem concluir, porém, que esses processos não chegaram a se configurar como transformações fonéticas (ou "leis fonéticas") e sua ocorrência se manteve como esporádica neste período específico da língua latina.

Os casos de apofonia, por sua vez, não se encontram relacionados aos diferentes registros de fala empregados por Petrônio ao longo do Satyricon, já que ocorrem de maneira assistemática nos diferentes grupos de episódios da narrativa. A ausência de correlação entre esses dois fatores considerados, diferentemente dos casos relativos aos processos de síncope e de monotongação, é aqui interpretada como um indício de que estas formas divergentes possam ter sido alteradas no decurso da transmissão, retratando o sistema vocálico da época posterior, em que foi feito o registro escrito.

Os dados analisados acima, no entanto, considerados como a descrição de um dos padrões fonéticos em uso durante o século I d.C., esboçam um quadro de grande instabilidade no sistema vocálico latino, que pode ser analisado como um período que teria precedido a fixação desses novos padrões em períodos posteriores da língua latina. 


\section{Referências Bibliográficas}

BIANCHET, Sandra Maria G. B. Satyricon, de Petrônio: estudo lingüístico e tradução. tese de doutorado. São Paulo: FFLCH-USP, 2002.

CLIMENT, MARIANO BASSOLS DE. Fonetica Latina. Madrid: Talleres Graficos Vda. de C. Bermejo, 1962.

DESBORDES, FRANÇOISE. Concepções sobre a Escrita na Roma Antiga. Tradução de Fulvia M. L. Moretto e Guacira Marcondes Machado. São Paulo: Editora Ática S.A., 1995.

FARIA, E. Fonética Histórica do Latim. 2. ed rev. e aum. Rio de Janeiro: Livraria Acadêmica, 1957.

. Gramática da Língua Latina. Revisão de Ruth Junqueira de Faria - 2. ed. rev. e aum. Brasília: FAE, 1995.

GAFFIOT, F. Dictionnaire Latin Français. Paris: Hachette, 1934.

HERRERO, VÍCTOR JOSÉ. Introducción al Estudio de la Filología Latina. $2^{\mathrm{a}}$ ed. (1 ${ }^{\mathrm{a}}$ reimpressão). Madrid: Editorial Gredos S.A., 1981.

JESPERSEN, OTTO. Language: its nature, development and origin. London: George Allen \& Unwin Ltd, 1949.

JURET, C. Dominance et Résistance dans la Phonétique Latine. Heidelberg: Carl Winter's Universitätsbuchhandlung, 1913.

LEUMANN, M., HOFMANN, J. B., SZANTYR, A. Lateinische Grammatik/Laut- und Formenlehre (erster Band). München: C.H. Beck'sche Verlagsbuchhadlung, 1963.

LEWIS \& SHORT. Oxford Latin-English Dictionary. New York: Oxford University Press, 1987.

MACHADO, RAÚL. Questões de Gramática Latina - Pronúncia do Latim e Elementos de Fonética Histórica Latina. Lisboa: Livraria Clássica Editora, 1940.

MANIET, ALBERT. La Phonétique Historique du Latin dans le Cadre des Langues Indoeuropéennes. 5. ed. aum. e corrig. Paris: Éditions Klincksieck, 1975.

MAURER JR., T. H. Gramática do Latim Vulgar. Rio de Janeiro: Livraria Acadêmica, 1959.

MONTEIL, P. Éléments de Phonétique et de Morphologie du Latin. Paris: Éditions Fernand Nathan, 1970.

NIEDERMANN, MAX. Précis de Phonétique Historique du Latin. 2. ed. rev. e aum. Paris: Librairie C. Klincksieck, 1931.

PALMER, L. R. The Latin Language. London: Faber and Faber Limited, 1954.

PETRÓNE. Le Satiricon. texte ét. et trad. par A. ERNOUT. Paris: "Les Belles Lettres", 1999.

QUINTILIEN. Instituition Oratoire. Texte établi et traduit par Jean Cousin. Paris: «Les Belles Lettres», 1975. 
202 Sandra Maria Gualberto Braga Bianchet: Alterações fonético-fonológicas no latim do século I d.C: descrição do sistema vocálico latino a partir do Satyricon, de Petrônio.

ROHLFS, GERHARD. Vom Vulgärlatein zum Altfranzösischen. $2^{\mathrm{a}}$ ed. rev. e aum. Tübigen: Max Niemeyer Verlag, 1963.

VÄÄNÄNEN, VEIKKO. Introducción al Latín Vulgar. Tradução para o espanhol de Manuel Carrión. Madrid: Editorial Gredos, 1985.

WILlIAMS, EDWIN B. Do Latim ao Português. Tradução de Antônio Houaiss. Rio de Janeiro: Instituto Nacional do Livro, 1961.

BIANCHET, Sandra Maria G. B. Phonetic and phonological changes in first century A.D. Latin: description of Latin vocalic system from data of Petronius's Satyricon. Classica, São Paulo, v. 15/16, n. 15/16, p. 189-202, 2002/2003.

ABSTRACT: The study of phonetic and phonological changes in languages such as Latin, from which we have only written documents present bigger difficulties, since the manuscripts are not contemporaneous with its authors. Besides this limitation, we intend to demonstrate that it is possible to make the description of the linguistic system at work during a certain period of the considered language using data from texts such as Petronius's Satyricon, in which the author expresses different speech registers.

KEYWORDS: Petronius; Satyricon; vulgar Latin; phonetics; phonology; vocalic system. 